\title{
Research on Compound Sliding Mode Control of a Permanent Magnet Synchronous Motor in Electromechanical Actuators
}

\author{
Jiachun Lin ${ }^{1, *(\mathbb{D}}$, Yuteng Zhao ${ }^{1}\left(\mathbb{D}\right.$, Pan Zhang ${ }^{1}$, Junjie Wang ${ }^{2}$ and Hao $\mathrm{Su}^{1}$ \\ 1 Beijing Engineering Research Center of Precision Measurement Technology and Instruments, \\ Department of Instrument Science and Technology, Faculty of Materials and Manufacturing, \\ Beijing University of Technology, No. 100, Ping Le Yuan, Chaoyang District, Beijing 100124, China; \\ Zhaoyt@emails.bjut.edu.cn (Y.Z.); zpzp@emails.bjut.edu.cn (P.Z.); suh123@emails.bjut.edu.cn (H.S.) \\ 2 The 45th Research Institute of China Electronics Technology Group Corporation, Taihe Third Street, \\ Daxing District, Beijing 100176, China; cuixl@emails.bjut.edu.cn \\ * Correspondence: linjc@bjut.edu.cn
}

check for updates

Citation: Lin, J.; Zhao, Y.; Zhang, P.; Wang, J.; Su, H. Research on Compound Sliding Mode Control of a Permanent Magnet Synchronous

Motor in Electromechanical

Actuators. Energies 2021, 14, 7293.

https://doi.org/10.3390/en14217293

Academic Editors: Mojtaba

Ahmadieh Khanesar and

Amin Hajizadeh

Received: 28 August 2021

Accepted: 26 October 2021

Published: 4 November 2021

Publisher's Note: MDPI stays neutral with regard to jurisdictional claims in published maps and institutional affiliations.

Copyright: (c) 2021 by the authors. Licensee MDPI, Basel, Switzerland. This article is an open access article distributed under the terms and conditions of the Creative Commons Attribution (CC BY) license (https:/ / creativecommons.org/licenses/by/ $4.0 /)$.

\begin{abstract}
In order to improve the response speed and disturbance rejection ability of a permanent magnet synchronous motor (PMSM) in an electromechanical actuator (EMA), a compound sliding mode control (CSMC) is proposed. The CSMC consists of a sliding mode controller with a new reaching law and disturbance observer based on a symmetric S-type function. The stability of the CSMC is analyzed using the Lyapunov stability analysis. The effectiveness of the CSMC is confirmed by the Simulink simulation, and experiments were conducted on a semi-physical platform. The results obtained by comparing the CSMC with the proportional integral (PI) control and traditional sliding mode control show that the CSMC has a faster response and stronger disturbance rejection ability and reduces chattering.
\end{abstract}

Keywords: electromechanical actuator (EMA); permanent magnet synchronous motor (PMSM); compound sliding mode control (CSMC); symmetric S-type function disturbance observer (SSFDO)

\section{Introduction}

Electromechanical actuators (EMAs) consist of a motor, a reducer, a driver, a controller, sensors, etc. [1], that can realize linear or rotary motion. EMAs are widely used in aerospace, military, robotics, transportation, equipment processing, and other fields due to their advantages of having high integration, a small size, high precision, and high efficiency [2,3]. Permanent magnet synchronous motors (PMSMs) are commonly used in EMAs because of their simple structure, light weight, high-power density, and good dynamic response [4]. However, PMSMs are nonlinear multivariable strong coupling systems, and their operating performance is easily influenced by unmodeled phenomena, parameter uncertainty, and external load. An EMA servo system requires a fast response and disturbance rejection ability, but the actual work environment is complex: frequent start-stops, continuous load changing, and so on $[5,6]$. Therefore, the traditional proportional-integral-differential controller cannot meet the requirements of the high performance and high precision control of the PMSM in EMAs. Sliding mode control (SMC) is commonly used in PMSMs control in EMAs due to its simple structure, fast response, strong disturbance rejection ability, insensitivity to model uncertainty, and good robustness $[7,8]$.

The SMC can improve the disturbance rejection ability and optimize the motor performance because of the structural characteristics, but it brings the chattering problem to the servo system, which seriously affects the control performance of the system [9]. Currently, reducing the high-frequency chattering and improving the disturbance rejection ability of the SMC are the research hotspots of researchers. An improved reaching law speed sliding mode controller was proposed by Liu Yangqing [10], and the sigmoid function was used to replace the switching function, which effectively reduced the chattering of the SMC and improved the response speed. However, the influence of external 
load disturbance was not considered. Based on the traditional exponential reaching law, Lin Chengmei [11] introduced a variable exponential function and a hyperbolic tangent function to improve the reaching speed and disturbance rejection ability. Zhou Yang [12] studied a new exponential reaching law with strong adaptive ability. The constant speed term was improved to the time variable, which solved the problem of the slow convergence of the traditional exponential reaching law system. The saturation function of the variable boundary layer was also used to replace the switching function, which reduced chattering. Yan Hongliang [13] proposed an improved reaching law sliding mode speed controller for a time-varying disturbance environment, which improved the dynamic performance of the system and reduced chattering. Moreover, the reaching law had no other parameters, which avoided the difficulty of parameter tuning. Xiong Hualiang [14] designed a supertwisting speed sliding mode controller to replace the q-axis PI controller, and changed the SGN function into a continuous sign function to suppress the torque and speed ripple. Zhou Caijin [15] designed a fractional sliding mode controller for a PMSM speed control system. The fractional order reaching law was used to suppress chattering. The simulation and experimental results showed that a faster response and better stability was achieved. Based on the traditional sliding mode observer, the sigmoid function was introduced as the switching function by Wu Dinghui [16], whereas the variable sliding mode gain method was used to reduce the high-frequency chattering. The tracking and disturbance rejection ability of the controller were verified using experiments. Although the above methods improve the response ability of the system and weaken the sliding mode chattering, they do not consider the influence of the external load disturbance and internal uncertainty of the system.

The EMA servo system should have good stability, a good tracking performance, a short settling time, and a strong disturbance rejection ability, etc. However, external load disturbances and internal uncertainties affect the stability of the EMA. Therefore, a disturbance observer should be introduced to estimate the disturbance and reduce its impact [17]. Yong-chao Liu [18,19] proposed a second-order sliding mode controller based on a Hermite neural network. In the speed loop, a disturbance observer based on the HNN was used to compensate both the external disturbance and internal parameter uncertainty. At the same time, a complementary sliding mode speed controller based on a disturbance observer was also proposed. A good tracking performance and high robustness were achieved by both methods. Chen Dai [20] designed a new current-constrained controller, and used the disturbance observer to estimate the mismatched disturbance. Lizhi Qu [21] proposed a sliding mode speed controller based on an extended state observer for the speed tracking control of a PMSM drive system under different disturbances. Zhu Dehong [22] studied a sliding mode controller based on a new variable exponential multi-power reaching law, and designed a new extended sliding mode disturbance observer to estimate the disturbance, which was then fed forward to the sliding mode controller. The results showed that the influence of the system disturbance was eliminated. To solve the problem of disturbance, an adaptive inversion sliding mode controller based on a nonlinear disturbance observer was designed by Lou Peibin [23]. The switching gain was adjusted using the adaptive law to reduce the chattering of the system and improve the disturbance rejection ability. An integral sliding mode controller was designed by Li Zheng [24] to eliminate the steady-state error. The load torque observer was designed according to the principle of the Luenberger linear observer, and the observed value of the sliding mode controller was recorded. However, there was difficulty in selecting the integral initial value, and the disturbance rejection ability was low. Furthermore, Zhao Feng [25] proposed a new reaching law based on a piecewise function to reduce the sliding mode chattering, and observed the motor disturbance using the extended state observer (ESO). The disturbance observation value was compensated as a feedforward signal to the sliding mode controller, which effectively reduced the sliding mode chattering and improved the accuracy of the torque estimation. However, the controller's parameter setting is complex and difficult. 
In this paper, a SMC is proposed for the speed control of PMSMs to improve the overall performance of the EMA servo system. This approach aims at meeting requirements of the fast response and strong disturbance rejection ability of the PMSM in EMAs. A new reaching law is designed to reduce chattering in the SMC, where the symbol function in the traditional SMC is replaced with the symmetric S-type function. A symmetric Stype function disturbance observer (SSFDO) is designed to observe the uncertainties in PMSMs, such as the external load disturbance and internal parameter uncertainty. In order to suppress the speedy fluctuation caused by the disturbance and the chattering of the controller and to improve the disturbance rejection ability of the system, the observed value as a feedback signal is compensated to the new sliding mode controller to form a compound SMC (CSMC). The stability of the CSMC is analyzed using the Lyapunov equation. Both the simulation and experimental of the motor speed control and disturbance observations were conducted using the MATLAB/Simulink simulation and a semi-physical platform, which proves the feasibility of the combination method of a SMC and a disturbance observer.

\section{Mathematical Model of PMSMs}

The core design of an EMA is the PMSM control method. To simplify the analysis, it is assumed that the three-phase PMSM has a symmetrical current, and the core saturation, eddy current, and hysteresis losses can be ignored. Then, the stator voltage equation in the $\mathrm{d}-\mathrm{q}$ synchronous rotating coordinate system is [26]

$$
\left\{\begin{array}{l}
u_{\mathrm{d}}=R i_{\mathrm{d}}+L_{\mathrm{d}} \frac{\mathrm{d}}{\mathrm{dt}} i_{\mathrm{d}}-\omega_{\mathrm{e}} L_{\mathrm{q}} i_{\mathrm{q}} \\
u_{\mathrm{q}}=R i_{\mathrm{q}}+L_{\mathrm{q}} \frac{\mathrm{d}}{\mathrm{dt}} i_{\mathrm{q}}+\omega_{\mathrm{e}}\left(L_{\mathrm{d}} i_{\mathrm{d}}+\varphi_{\mathrm{f}}\right)
\end{array},\right.
$$

the electromagnetic torque equation is [26]

$$
T_{\mathrm{e}}=\frac{3}{2} p_{\mathrm{n}} i_{\mathrm{q}}\left[i_{\mathrm{d}}\left(L_{\mathrm{d}}-L_{\mathrm{q}}\right)+\varphi_{\mathrm{f}}\right]
$$

and the mechanical motion equation is [26]

$$
J \frac{\mathrm{d}}{\mathrm{dt}} \omega=T_{\mathrm{e}}-T_{\mathrm{L}}-B \omega
$$

The parameters $u_{\mathrm{d}}$ and $u_{\mathrm{q}}$ are the voltage components and $i_{\mathrm{d}}$ and $i_{\mathrm{q}}$ are the current components of the $\mathrm{d}-\mathrm{q}$ axis, respectively. $R$ is the stator resistance, and $L_{\mathrm{d}}$ and $L_{\mathrm{q}}$ are the inductance components of the $\mathrm{d}-\mathrm{q}$ axis. $\varphi_{\mathrm{f}}$ and $\omega_{\mathrm{e}}$ are the stator flux linkage and angular velocity of the motor, respectively. $\omega$ is the mechanical angular velocity of the motor. $T_{\mathrm{e}}$ is electromagnetic torque. $P_{\mathrm{n}}$ is the pole number of the motor. $T_{\mathrm{L}}$ is the load. $B$ is the damping coefficient. $J$ is the rotational inertia of the rotor.

If the PMSM has a surface-mounted rotor, then $L_{\mathrm{d}}=L_{\mathrm{q}}=L$. Additionally, when the the field-oriented control method with $i_{\mathrm{d}}=0$ is used, the mathematical model of the PMSM can be expressed as follows:

$$
\left\{\begin{array}{l}
\frac{\mathrm{d}}{\mathrm{dt}} i_{\mathrm{q}}=\frac{1}{L}\left(u_{\mathrm{q}}-R i_{\mathrm{q}}-p_{\mathrm{n}} \omega \varphi_{\mathrm{f}}\right) \\
\frac{\mathrm{d}}{\mathrm{dt}} \omega=\frac{1}{J}\left(1.5 P_{\mathrm{n}} \varphi_{\mathrm{f}} i_{\mathrm{q}}-T_{\mathrm{L}}-B \omega\right)
\end{array} .\right.
$$

\section{Design of a Compound Sliding Mode Controller}

\subsection{Design of a Traditional Sliding Mode Controller}

The SMC is a nonlinear control method with a variable structure. The nonlinear control means that the state is discontinuous. The variable structure means that the controller output is changed according to the current state of the system, so that the state vector moves along the predefined state trajectory. In Figure 1, the AB section is the reaching phase, which means that the system state continuously approaches the sliding surface from any position away from the sliding surface and arrives within a certain time. The BC section is the sliding phase, where the system state moves along the sliding surface to the 
equilibrium point. Therefore, the design of a sliding mode controller includes the selection of the sliding surface and the design of the reaching law. These designs are independent of the parameters and disturbances of a servo system; thus, the SMC is highly robust.

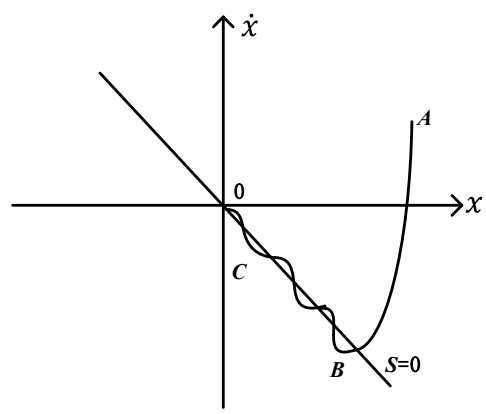

Figure 1. State trajectory of the sliding mode control (SMC) system.

In a traditional sliding mode speed controller, a differential sliding mode surface is generally adopted, and the function is as follows:

$$
s=c x+\dot{x}
$$

where, $c$, greater than 0 , is the parameter to be designed. The exponential reaching law [27] is generally used as:

$$
\dot{s}=-\varepsilon \operatorname{sgn}(s)-k s
$$

The speed tracking error of the PMSM is defined as:

$$
x=\omega_{\text {ref }}-\omega,
$$

where $\omega_{\text {ref }}$ is the reference angular velocity and $\omega$ is the actual angular velocity of the motor. According to the mathematical model of the PMSM, the first and second order derivatives of $x$ are:

$$
\left\{\begin{array}{l}
\dot{x}=-\dot{\omega}=-\frac{1}{J}\left(1.5 P_{\mathrm{n}} \varphi_{\mathrm{f}} i_{\mathrm{q}}-T_{\mathrm{L}}-B \omega\right) \\
\ddot{x}=-\ddot{\omega}=-\frac{1}{J}\left(1.5 P_{\mathrm{n}} \varphi_{\mathrm{f}} \frac{\mathrm{d} i_{\mathrm{q}}}{\mathrm{dt}}-B \dot{\omega}\right)
\end{array} .\right.
$$

Denote $D=\frac{1.5 P_{\mathrm{n}} \varphi_{\mathrm{f}}}{J}$ and $u=\frac{\mathrm{d} i_{\mathrm{q}}}{\mathrm{dt}}$, then the derivative of Equation (5) is combined with Equation (8) to obtain:

$$
\dot{s}=c \dot{x}-D u+\frac{B}{J} \dot{\omega} .
$$

Therefore, according to Equations (6) and (9), the output of the traditional sliding mode controller is:

$$
u=\frac{1}{D}\left[c \dot{x}+\frac{B}{J} \dot{\omega}+\varepsilon \operatorname{sgn}(s)+k s\right] .
$$

\subsection{Reaching Law Design Based on New Symmetric S-Type Function}

Fast reaching and low chattering cannot be considered at the same time in a traditional sliding mode controller with exponential reaching law. Therefore, by combining the exponential and power reaching laws, the new reaching law is obtained:

$$
\dot{s}=-\varepsilon|x|^{a} \operatorname{sgn}(s)-k|x|^{b} s,
$$

where $s$ is a sliding surface function. $\varepsilon, k, a$, and $b$ are the parameters to be designed. $x$ is the system state variable, which represents the difference between the actual speed and the reference speed. 
When the system state point is far from the sliding surface, $s$ and $x$ are large, and the new reaching law can be rewritten as Equation (12). Consequently, the state point moves toward the sliding surface with the combination speed of the two items.

$$
\dot{s}=-\varepsilon|x|^{a}-k|x|^{b} s .
$$

When the system state point is close to the sliding surface, $s$ and $x$ are very small, and the new reaching law can be expressed as Equation (13). The variable exponent term reaches zero, and the variable speed term dominates the movement of the state.

$$
\dot{s}=-\varepsilon|x|^{a} \operatorname{sgn}(s),
$$

With SMC, the system state point moves to the origin along the sliding surface and finally stabilizes at the origin. Therefore, the variable speed term decreases continuously in this process so that the system state point will not have a high-frequency oscillation near the sliding surface due to the velocity inertia. The system chattering is reduced.

The symbolic function $\operatorname{sgn}(s)$ is a discontinuous switching function, which switches instantaneously near the zero point. Therefore, high-frequency chattering is generated when the system state point moves along the sliding surface. In order to improve the disturbance rejection ability and reduce the chattering of the controller, this study uses the continuous symmetric S-type function instead of the symbolic function. The symmetric S-type function equation is as follows

$$
\mathrm{f}(s)=\frac{1-e^{-\alpha s}}{1+e^{-\alpha s}}
$$

where $\alpha>0$, and its value determines how fast the value of the symmetric S-type smooth function changes near the origin. The switch and symmetric S-type function are shown in Figure 2. When $\alpha$ is infinite, $\mathrm{f}(s)$ can be converted to a switch function, which can cause large chattering. When $\alpha$ is very small, the boundary layer thickness is large, the system convergence is slow, and the robustness is poor. To meet the requirements of the high precision and good robustness of the system, $\alpha=2$ is selected in the study. This maintains the switching characteristics of SMC and effectively reduces the discontinuity of the system, thereby reducing the chattering and improving the disturbance rejection ability.

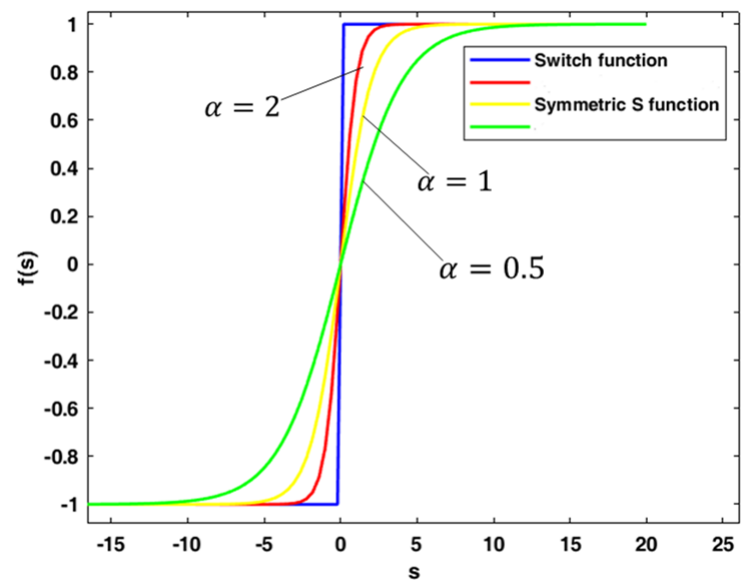

Figure 2. Switch function and symmetric S-type function.

Therefore, the new reaching law based on the symmetric S-type function is shown in Equation (15), where $\varepsilon>0, k>0, a, b \in[0,1]$, and $\alpha=2$.

$$
\left\{\begin{array}{ll}
\dot{s} & =-\varepsilon|x|^{a} \mathrm{f}(s)-k|x|^{b} s \\
\mathrm{f}(s) & =\frac{1-e^{-2 s}}{1+e^{-2 s}}
\end{array} .\right.
$$




\subsection{Design of a New Sliding Mode Controller and Its Stability Analysis}

The new sliding mode controller can be obtained from Equations (9) and (15) as

$$
u=\frac{1}{D}\left[c \dot{x}+\frac{B}{J} \dot{\omega}+\varepsilon|x|^{a} \mathrm{f}(s)+k|x|^{b} s\right]
$$

and the reference current of q-axis can be obtained by integrating Equation (16) as

$$
i_{\mathrm{q}}^{*}=\frac{1}{D} \int\left[c \dot{x}+\frac{B}{J} \dot{\omega}+\varepsilon|x|^{a} \mathrm{f}(s)+k|x|^{b} s\right] \mathrm{dt} .
$$

To verify the stability of the system, the Lyapunov function is built as follows [28]

$$
\mathrm{V}=\frac{1}{2} s^{2}
$$

whereas the derivative of $\mathrm{V}$ is obtained by combining Equation (15)

$$
\dot{V}=s \dot{s}=\mathrm{s}\left[-\varepsilon|x|^{a} \mathrm{f}(s)-k|x|^{b} s\right]=-s \varepsilon|x|^{a} \mathrm{f}(s)-k|x|^{b} s^{2},
$$

where, $\varepsilon>0, k>0,|x|^{a}>0,|x|^{b}>0$, and $\mathrm{f}(s)$ is an odd function; hence, for any sliding surface, $\dot{V} \leq 0$. Based on the stability theory, the new SMC system proposed in this study can converge to a stable state in finite time.

\subsection{Design of Symmetric S-Type Function Disturbance Observer}

Here, a differential sliding surface is used. In the second derivative of the velocitytracking error, the influence of external load disturbance is ignored. However, the external load is variable in the practical application of EMAs. The ignorance of the external load will lead to the oscillation of the EMA output, which should be avoided. Therefore, it is necessary to design an observer to observe the external load and feedforward compensation to the new sliding mode controller. By introducing such a design, the performance of the SMC, stability of the EMA operation, and control accuracy are improved.

The sampling frequency of the controller is usually much greater than the change time of the load torque, so the load torque can be considered a constant value in a sampling period; that is, $\dot{T}_{\mathrm{L}}=0$. Combined with the mechanical motion and electromagnetic torque equations of PMSMs, the motor angular velocity $\omega$ and the load torque $T_{\mathrm{L}}$ are designed as state variables. The q-axis current is used as an input, and the estimated angular velocity and observed load torque are used as outputs. Therefore, the state space and disturbance observer equations of PMSMs are shown in Equations (20) and (21), respectively

$$
\begin{gathered}
\left\{\begin{array}{l}
\dot{\omega}=\frac{1.5 P_{\mathrm{n}} \varphi_{\mathrm{f}}}{J} i_{\mathrm{q}}-\frac{T_{\mathrm{L}}}{J}-\frac{B}{J} \omega, \\
\dot{T}_{\mathrm{L}}=0
\end{array}\right. \\
\left\{\begin{array}{l}
\hat{\dot{\omega}}=\frac{1.5 P_{\mathrm{n}} \varphi_{\mathrm{f}}}{J} i_{\mathrm{q}}-\frac{\hat{T}_{\mathrm{L}}}{J}-\frac{B}{J} \omega+U, \\
\hat{\vec{T}}_{\mathrm{L}}=l U
\end{array}\right.
\end{gathered}
$$

where, $\hat{\omega}$ is the estimated motor angular velocity; $\hat{T}_{\mathrm{L}}$ is the observed load torque; $l$ is the feedback gain of the disturbance observer; $U$ is the SMC rate, which is defined as $U=-\beta \mathrm{f}(s)-\gamma s$, where $\beta$ and $\gamma$ are the gains of the SMC rate; $s$ is the sliding surface; and $\mathrm{f}(s)$ is the symmetric S-type function. Subtracting Equation (20) from Equation (21), the error equations of the observer become.

$$
\left\{\begin{array}{l}
\dot{e}_{1}=\hat{\dot{\omega}}-\dot{\omega}=-\frac{e_{2}}{J}+U \\
\dot{e}_{2}=\hat{\dot{T}}_{\mathrm{L}}-\dot{T}_{\mathrm{L}}=l U
\end{array} .\right.
$$


In Equation (22), $e_{1}$ and $e_{2}$ are the speed estimation and load torque observation error, respectively. The sliding mode switching surface $s=e_{1}=0$ is defined. From the sliding mode accessibility condition, $\mathrm{s} \dot{s} \leq 0$, which can be obtained as

$$
\dot{s} \dot{S}=e_{1} \dot{e}_{1}=e_{1}\left[-\frac{e_{2}}{J}+U\right]=e_{1}\left[-\frac{e_{2}}{J}-\lambda \mathrm{f}\left(e_{1}\right)-\gamma e_{1}\right] \leq 0 .
$$

In Equation (23), $\gamma>0$ and $\lambda \geq \frac{\left|e_{2}\right|}{J}>0$. When the system state point reaches the sliding surface and moves along the sliding surface, $e_{1}=0$. Substituting Equation (22) into Equation (23), we have

$$
e_{2}=h e^{\frac{l}{t}},
$$

where $h$ is a constant. As long as the value of $l$ is less than $0, e_{2} \approx 0$; then, the load torque can be observed. Based on the above analysis, the structural diagram of the SSFDO is shown in Figure 3.

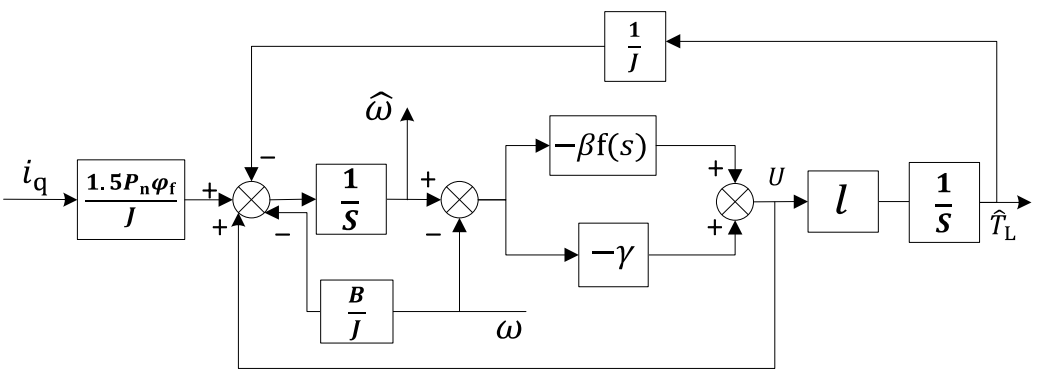

Figure 3. Structure diagram of the symmetric S-type function disturbance observer (SSFDO).

\subsection{Design of Compound Sliding Mode Controller Based on SSFDO}

In this study, the new reaching law and continuous symmetric S-type function are used in the new sliding mode controller designed. The speed of the reaching phase is accelerated, the time to reach the steady state is reduced, and the chattering of the system is reduced to some extent. However, the influence of the external load disturbance and internal parameter change on the system is ignored. In order to improve the disturbance rejection ability of the system, the SSFDO is used to observe the change in load disturbance in real time. The observation torque $\hat{T}_{\mathrm{L}}$ is feedforward compensated to the new sliding mode controller to form a compound sliding mode controller, enhance the control effect, and improve the robustness of the system. Finally, the expression of the CSMC based on the SSFDO is shown in Equation (25), whereas the overall system control block diagram is shown in Figure 4.

$$
i_{\mathrm{q}}^{*}=\frac{1}{D}\left[\int\left[c \dot{x}+\frac{B}{J} \dot{\omega}+\varepsilon|x|^{a} \mathrm{f}(s)+k|x|^{b} s\right] \mathrm{dt}+\frac{\hat{T}_{\mathrm{L}}}{J}\right] .
$$

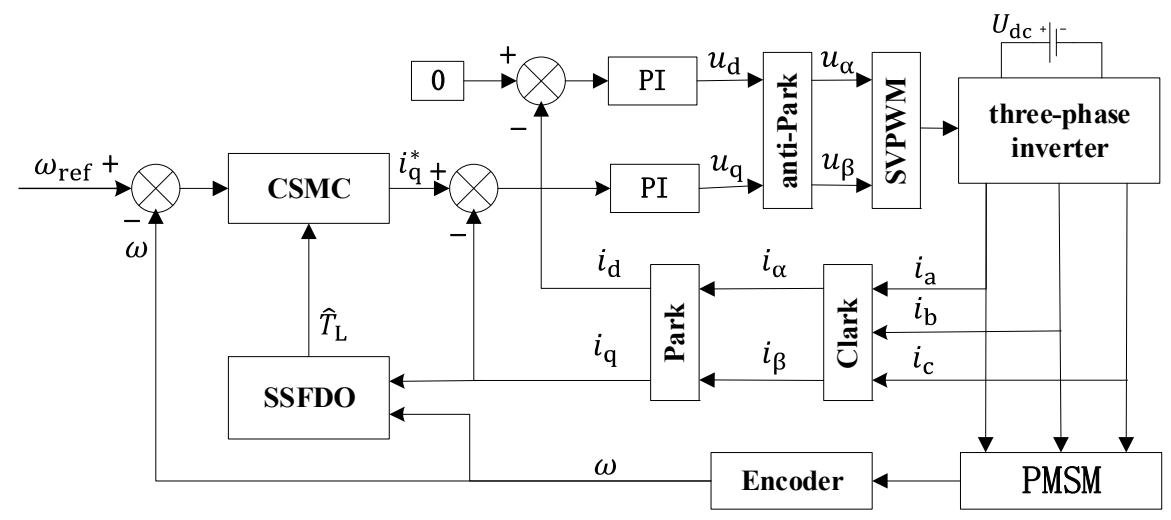

Figure 4. Block diagram of the compound sliding mode control (CSMC) system based on SSFDO. 


\section{Simulation and Experimental Results Analysis}

In order to verify the feasibility of the compound sliding mode controller, both the simulation and experimental verification were carried out using the MATLAB/Simulink simulation and the Links-RT-PMSM servo platform. The parameters of the PMSM and the test bed are shown in Table 1.

Table 1. Parameters of PMSM and test bed.

\begin{tabular}{cc}
\hline Parameters & Numerical Value \\
\hline Rated power $(\mathrm{W})$ & 100 \\
Rated output speed $(\mathrm{RPM})$ & 3000 \\
Rated output torque $(\mathrm{N} \cdot \mathrm{m})$ & 0.318 \\
Polar logarithm & 4 \\
Line inductance $(\mathrm{mH})$ & $21 \mathrm{kHz}, 1 \mathrm{v}$ \\
Line resistance $(\Omega)$ & 0.75 \\
Back EMF coefficient $(\mathrm{mV} / \mathrm{rpm})$ & 5.35 \\
Rotor inertia $\left(\mathrm{kg} \cdot \mathrm{m}^{2} \cdot 10^{-4}\right)$ & 0.0588 \\
Weight $(\mathrm{kg})$ & 0.8 \\
Encoder $(\mathrm{PPR})$ & 1250 \\
Switching frequency of the inverter $(\mathrm{KHz})$ & 20 \\
Deadtime set in experimental tests $(\mu \mathrm{s})$ & 2.5 \\
\hline
\end{tabular}

\subsection{Analysis of Simulation Results}

The system simulation model is shown in Figure 5. The simulation time of the system is set as $0.4 \mathrm{~s}$, and the sampling period is set as $10 \mu \mathrm{s}$. The control strategy with $i_{\mathrm{d}}=0$ is adopted, and the results of the CSMC are compared with the traditional SMC and the PI control.

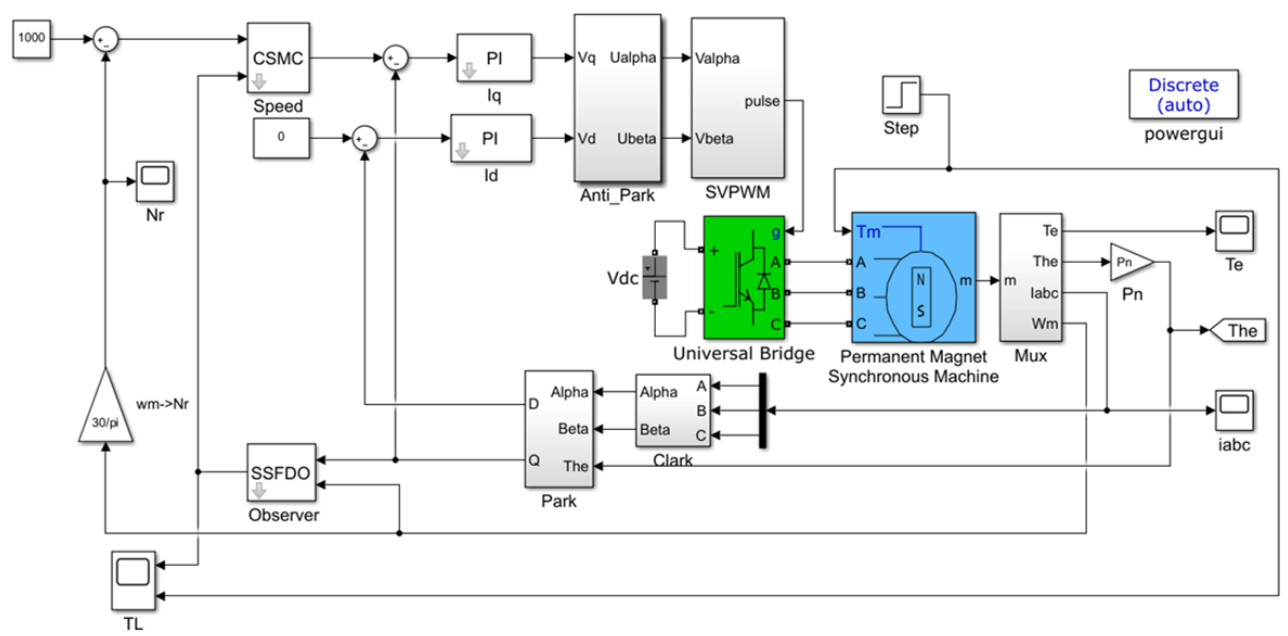

Figure 5. System simulation model.

\subsubsection{Simulation Analysis of SSFDO}

In order to verify the observation effect of the load disturbance observer, the motor is set to start without the load and the $5 \mathrm{~N} \cdot \mathrm{m}$ load torque is suddenly applied at $t=0.2 \mathrm{~s}$. The gain values in SSFDO are $\beta=2, \gamma=4000$, and $l=-4$. The observation results are shown in Figure 6, where TL is the given torque waveform and TL1 is the observation torque waveform. Figure 6a shows the response time when the observation torque reaches the given torque value. Figure $6 \mathrm{~b}$ shows the fluctuation of the observed torque. The cogging torque is caused by the special structure of the PMSM motor, which fluctuates the observed torque. Based on the annotation of (a) in Figure 6, the convergence time $\Delta t=0.005 \mathrm{~s}$ and convergence rate is fast. It can be seen from Figure $6 \mathrm{~b}$ that the fluctuation amplitude range is between $\pm 0.001 \mathrm{~N} \cdot \mathrm{m}$, the waveform oscillation is small, and the observation accuracy is high. 


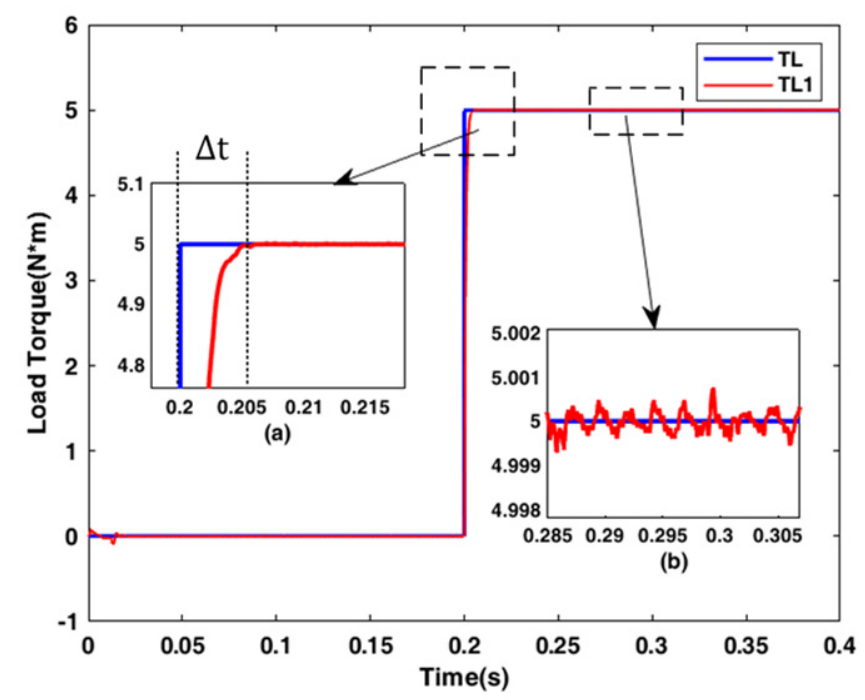

Figure 6. Observation results of load torque: (a) convergence time, (b) torque fluctuation.

In Figure 7, the speed change in the new SMC with or without the observation disturbance is compared. "New-SMC" represents the speed change curve under the control of the new sliding mode controller designed, whereas "SSFDO-CSMC" represents the speed curve under the compound sliding mode controller with the symmetrical S-type function disturbance observer. Figure 7 a shows the starting performance curve of the motor and Figure $7 \mathrm{~b}$ shows the disturbance rejection ability of the motor.

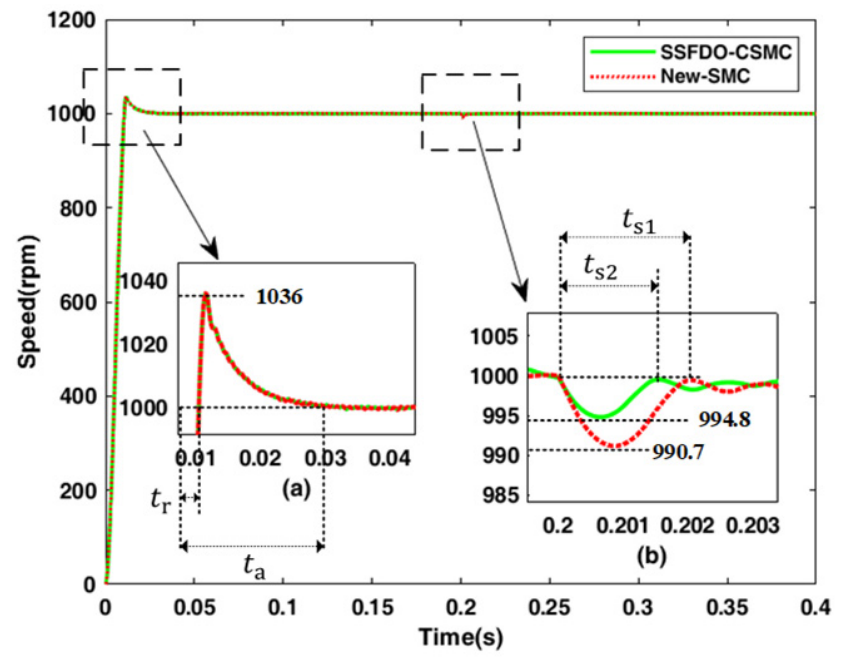

Figure 7. Speed response with or without observer: (a) starting performance, (b) disturbance rejection ability.

Furthermore, Figure 7a shows that the startup performance of the motor is consistent, regardless of the addition of the observation disturbance. It should be noted that when the rise time $t_{\mathrm{r}}=0.011 \mathrm{~s}$, the maximum speed is $1036 \mathrm{rpm}$ and the adjustment time $t_{\mathrm{a}}=0.029 \mathrm{~s}$. It can be seen from Figure $7 \mathrm{~b}$ that, after the load torque is increased, the speed controlled by the new sliding mode controller decreases to $990.7 \mathrm{rpm}$ and the time to recover to stability is $t_{\mathrm{s} 1}=0.002 \mathrm{~s}$. The speed controlled by the compound sliding mode controller is reduced to $994.8 \mathrm{rpm}$, and the time to recover to stability is $t_{\mathrm{s} 2}=0.0014 \mathrm{~s}$. Based on the above analysis, adding the observed disturbance can reduce the chattering caused by the load change and quicken the recovery time. 
4.1.2. Simulation Analysis of the Startup Performance and Disturbance Rejection Ability

The target speed is set to $1000 \mathrm{rpm}$. The speed and current loop parameters of the compound sliding mode, traditional sliding mode, and PI controller are set as shown in Table 2.

Table 2. Gain parameters of three control methods.

\begin{tabular}{ccc}
\hline Control Methods & Speed Loop & Current Loop \\
\hline \multirow{2}{*}{ PI control } & $K_{\mathrm{p}}=0.14$ & \\
& $K_{\mathrm{i}}=14.05$ & \\
& $c=260$ & \\
Traditional SMC & $\begin{array}{c}c .5 \times 10^{6} \\
k=40\end{array}$ & $K_{\mathrm{p}}=15$ \\
& $c=210$ & $K_{\mathrm{i}}=6$ \\
& $\varepsilon=4.5 \times 10^{6}$ & \\
& $k=40$ & \\
CSMC & $a=0.1, b=0.02$ & \\
& $\beta=2, \gamma=4000, l=-4$ & \\
\hline
\end{tabular}

In the CMSC, $a=0.1$ and $b=0.02$. Figure 8a shows the multiple of the speed reduction of the system point in the sliding phase under the CSMC. Figure $8 \mathrm{~b}$ shows the multiple of the speed increase of the system point in the reaching phase under the CMSC. As shown in Figure 8, compared with the traditional exponential reaching law SMC, when the system point is far away from the sliding surface, say, $x \gg 0$, the speed of the CSMC in the reaching motion stage increases by 1.1-2 times. When the system point reaches the sliding surface, say, $x \approx 0$, the speed of the CSMC in the sliding mode stage decreases by $0-0.6$ times. Therefore, the selection of $a$ and $b$ values meets the requirements of the acceleration of the system point in the reaching motion stage and deceleration in the sliding mode stage, which makes it difficult to cause the system chattering.

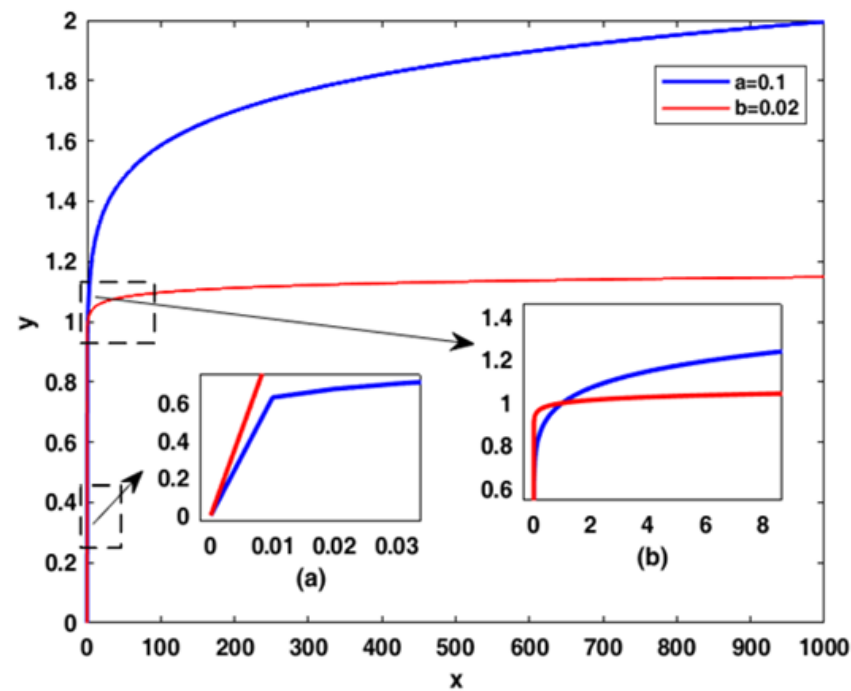

Figure 8. Function results of $y=|x|^{a}$ and $y=|x|^{b}$ : (a) multiple of the speed reduction, (b) multiple of the speed increase.

The starting speed performance and disturbance rejection ability of PMSM are simulated using the above three control methods. The speed changes are shown in Figure 9. Figure 9a shows the starting speed performance curve of the motor and Figure $9 \mathrm{~b}$ shows the disturbance rejection ability of the motor. 


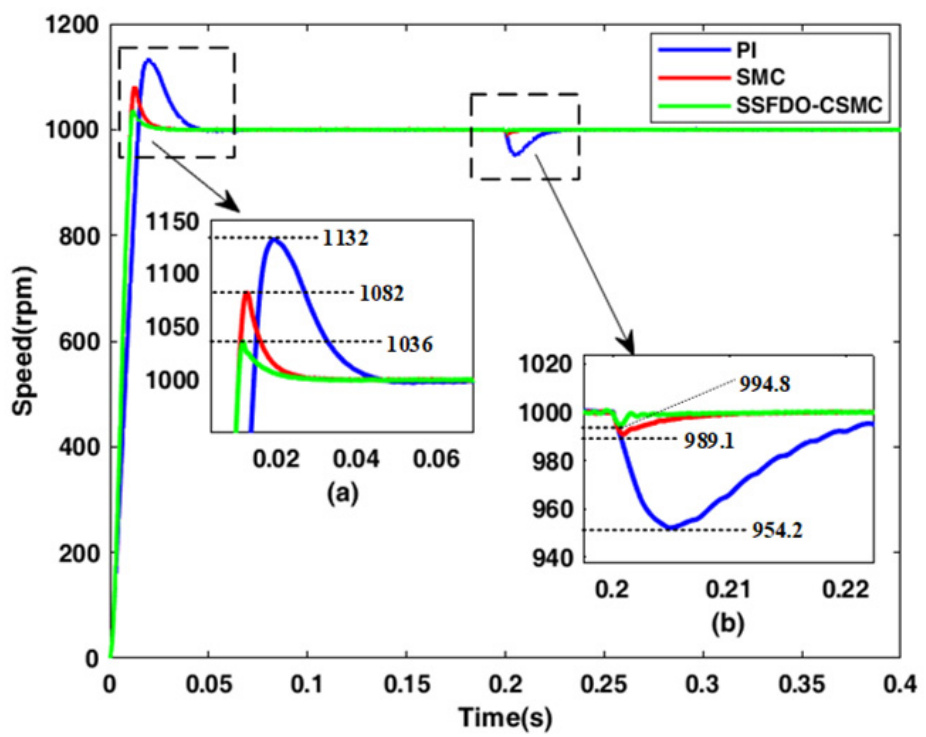

Figure 9. Speed response under step load of $5 \mathrm{~N} \cdot \mathrm{m}$ : (a) starting performance, (b) disturbance rejection ability.

Figure 9a shows that the speed rise under the PI control is the largest, whereas the rise time and time to recover to the steady state are longer. The speed overshoot of the traditional SMC is greater than that of the CSMC, and the time to recover to the steady state is longer than that of the CSMC under the same rise time. Furthermore, Figure $9 \mathrm{~b}$ shows that, under the same load disturbance, the CSMC has the smallest chattering and shortest recovery time, whereas the PI control has the largest chattering and longest recovery time. This shows that the disturbance rejection ability of the CSMC is strong.

Further, the motor is started without a load and the load step is suddenly added after a certain time. The motor speed overshoot, speed change in the disturbance rejection ability, and adjustment time of the three control methods are shown in Table 3. According to the data comparison in Table 3, the proposed CSMC designed is significantly better than the PI control and traditional SMC in the motor startup performance and disturbance rejection.

Table 3. Simulation speed changes and adjustment time under load mutation.

\begin{tabular}{cccc}
\hline Control Methods & PI Control & Traditional SMC & CSMC \\
\hline Rise time (s) & 0.014 & 0.011 & 0.011 \\
Maximum speed (rpm) & 1132 & 1082 & 1036 \\
Adjusting time (s) & 0.046 & 0.038 & 0.029 \\
Load speed (rpm) & 954.2 & 989.1 & 994.8 \\
Recovery time (s) & 0.034 & 0.018 & 0.0015 \\
Overshoot & $13.2 \%$ & $8.2 \%$ & $3.6 \%$ \\
\hline
\end{tabular}

\subsubsection{Simulation Analysis of the Performance under Speed Step with Constant Torque}

In the simulation, the initial speed was set to $1000 \mathrm{rpm}$, and a constant torque of $5 \mathrm{~N} \cdot \mathrm{m}$ was applied. Then, the speed was changed step by step, first decreasing from $1000 \mathrm{rpm}$ to $500 \mathrm{rpm}$, then increasing to $800 \mathrm{rpm}, 1000 \mathrm{rpm}, 1100 \mathrm{rpm}$, and finally returning to $1000 \mathrm{rpm}$. The simulation results are shown in Figure 10. Figure 10a shows the starting speed performance curve of the motor and Figure 10b shows the disturbance rejection ability of the motor. Figure 10c-e shows the starting speed performance of the motor at different step speeds. 


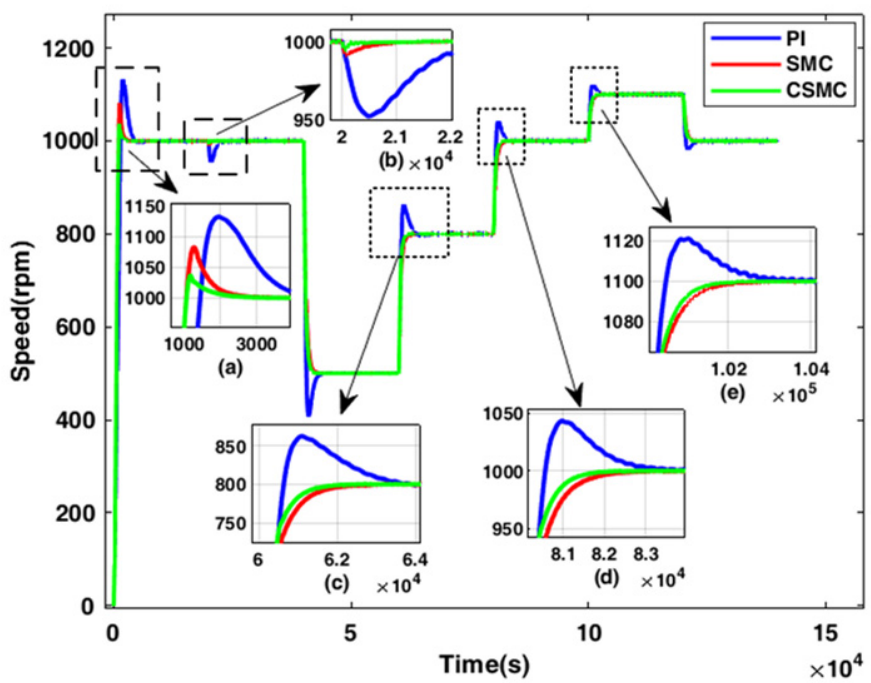

Figure 10. Performance response under speed step with $5 \mathrm{~N} \cdot \mathrm{m}$ torque: (a) starting performance, (b) disturbance rejection ability, (c-e) starting performance at different step speeds.

The results in Figure 10 show that the CSMC has the best tracking performance under the speed step with a constant torque of $5 \mathrm{~N} \cdot \mathrm{m}$. Compared with the PI control and traditional SMC, the CSMC can reach the target speed quickly and without overshoot.

\subsection{Analysis of the Experimental Results}

The servo control platform is shown in Figure 11. The no-load and on-load experiments under the PI control, traditional SMC, and CSMC are conducted on the servo platform. The execution frequencies of the current and speed loops are $10 \mathrm{KHz}$ and $1 \mathrm{KHz}$, respectively, and the frequency of the recorded data is $1 \mathrm{KHz}$.

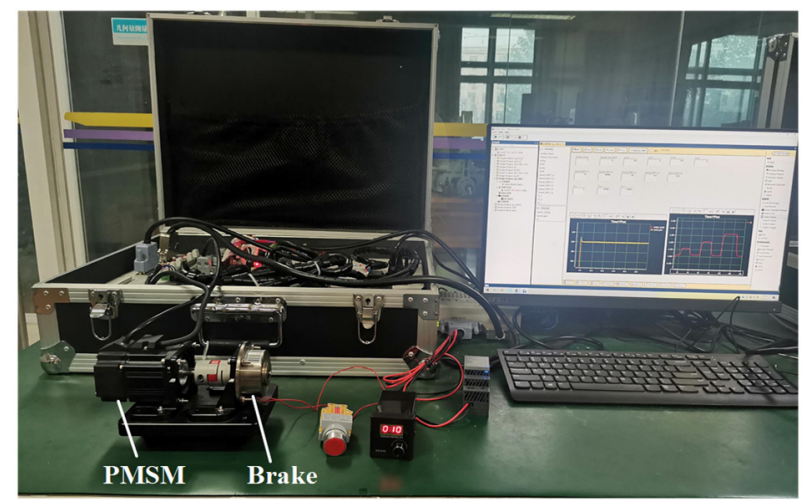

Figure 11. Permanent magnet synchronous motor (PMSM) servo control platform from Beijing Links Tech Co., Ltd.

\subsubsection{Experimental Verification of SSFDO}

The actual effect of the disturbance observer is verified by brake loading. In the actual test, the gain values of SSFDO are $\beta=0.01, \gamma=3$, and $l=-0.02$, whereas the observation effect of the load disturbance is shown in Figure 12. Figure 12a-c show the response time and fluctuation of the observed torque when the observed torque reaches different given torque values. The motor is set to start without a load, and the current of $0.1 \mathrm{~A}$ is suddenly loaded at $1.8 \mathrm{~s}$ and unloaded at $3.6 \mathrm{~s}$. It can be seen from Figure 12a that the torque observed by the observer is $0.112 \mathrm{~N} \cdot \mathrm{m}$. Then, the $0.2 \mathrm{~A}$ current is suddenly loaded at $4.9 \mathrm{~s}$ and unloaded at $7 \mathrm{~s}$. Figure $12 \mathrm{~b}$ shows that the torque observed by the observer is $0.215 \mathrm{~N} \cdot \mathrm{m}$. Figure $12 \mathrm{c}$ shows that there is a disturbance of $0.023 \mathrm{~N} \cdot \mathrm{m}$ when there is no load. 


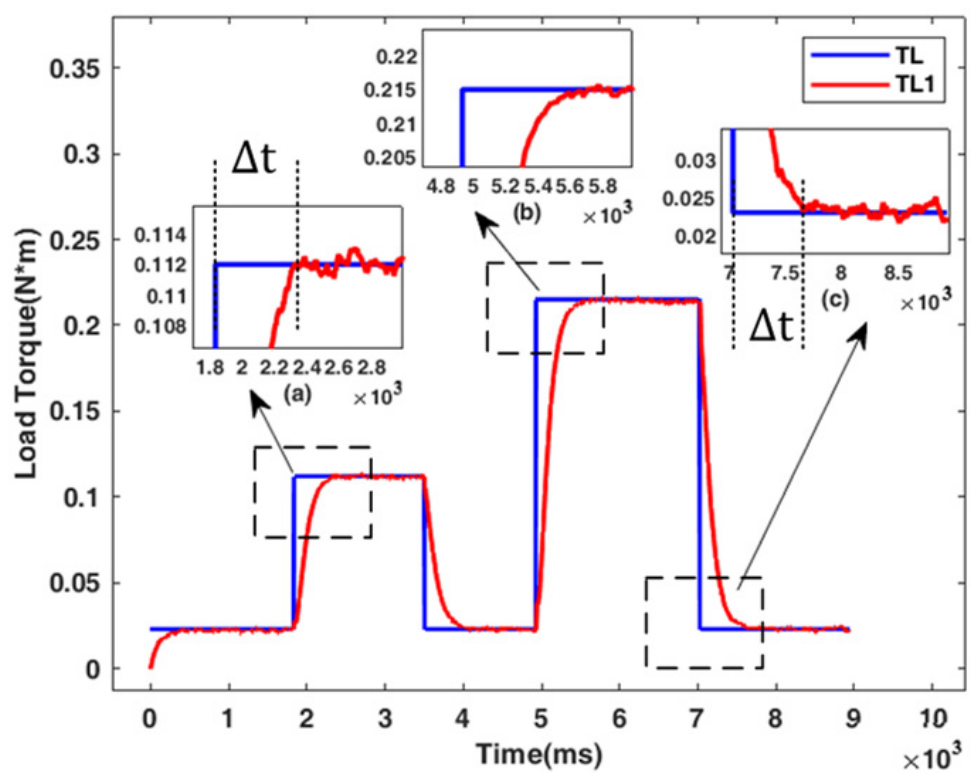

Figure 12. Actual observation results of load torque: (a-c) convergence time and torque fluctuation.

The torque values observed in Figure 12 are consistent with those in the standard torque characteristic curve. When the current increases twice, the torque also increases twice. The convergence and recovery time are $\Delta t=0.5 \mathrm{~s}$, and the fluctuation amplitude is between $\pm 0.001 \mathrm{~N} \cdot \mathrm{m}$. Therefore, the SSFDO designed in this study has a high observation accuracy and practical significance.

The comparison of the actual test of the speed changes in the CSMC based on SSFDO and the new SMC is shown in Figure 13. It can be seen from Figure 13a that the startup performance of the motor is identical whether the observation disturbance is added or not. As shown in Figure 13b, when the current load is increased by $0.1 \mathrm{~A}$ at $5.04 \mathrm{~s}$, the chattering caused by the CSMC is smaller than that of the new SMC, and the time to recover to stability is faster. The experimental and simulation results are shown in Table 4 . Based on the comparison of data with and without the observer in Table 4, it is proven that the proposed CSMC is effective.

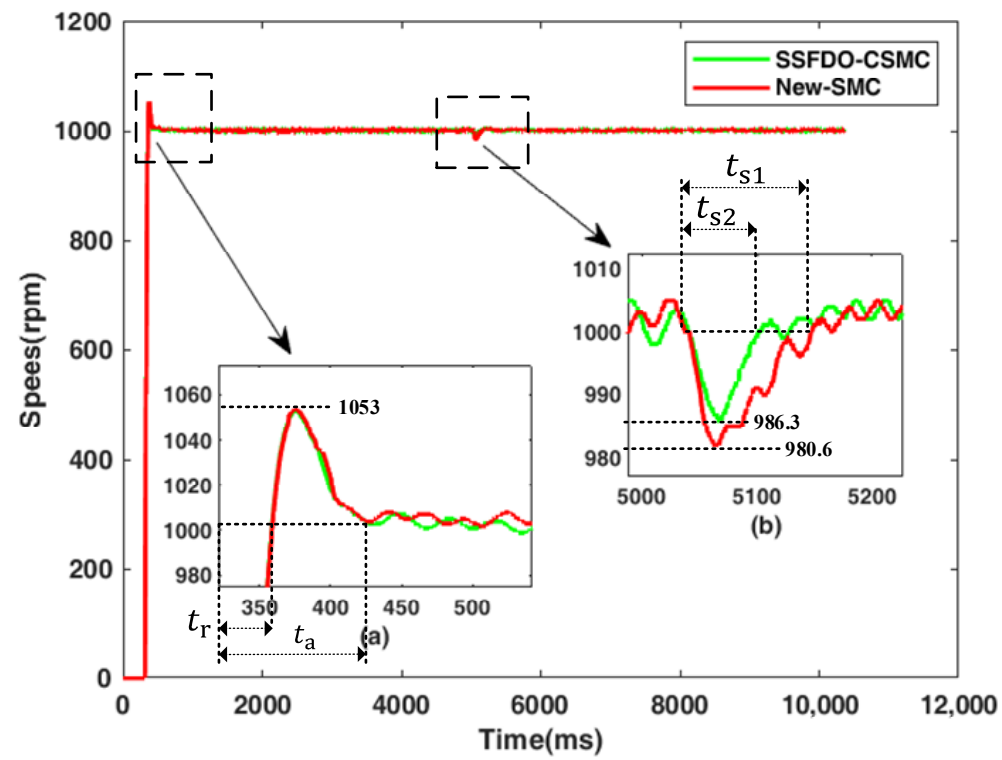

Figure 13. Actual speed response with or without observer: (a) starting performance, (b) disturbance rejection ability. 
Table 4. Comparison of the simulation and experimental results with and without an observer.

\begin{tabular}{cccc}
\hline Observer & Speed Change & Simulation Result & Experimental Result \\
\hline \multirow{2}{*}{ With/without } & Rise time (s) & 0.011 & 0.045 \\
& Maximum speed (rpm) & 1036 & 1053 \\
& Adjusting time (s) & 0.029 & 0.214 \\
\hline \multirow{2}{*}{ Without } & Load speed (rpm) & 990.7 & 980.6 \\
& Recovery time (s) & 0.002 & 0.107 \\
\hline \multirow{2}{*}{ With } & Load speed (rpm) & 994.8 & 986.3 \\
& Recovery time (s) & 0.0014 & 0.059 \\
\hline
\end{tabular}

4.2.2. Experimental Verification of the Startup Performance and Disturbance Rejection Ability

The target speed is set to $1000 \mathrm{rpm}$, and the load torque corresponding to $0.1 \mathrm{~A}$ is loaded at $5.0 \mathrm{~s}$. The parameter settings of the speed and current loops of the three control methods are shown in Table 5. The speed changes in the three control methods under the same load are shown in Figure 14. Figure 14a shows the starting speed performance curve of the motor and Figure 14b shows the disturbance rejection ability of the motor.

Table 5. Gain parameters of three control methods in the experimental test.

\begin{tabular}{|c|c|c|}
\hline Control Methods & Speed Loop & Current Loop \\
\hline PI control & $\begin{aligned} K_{\mathrm{p}} & =0.02 \\
K_{\mathrm{i}} & =0.01\end{aligned}$ & \multirow{3}{*}{$\begin{aligned} K_{\mathrm{p}} & =0.6 \\
K_{\mathrm{i}} & =16\end{aligned}$} \\
\hline traditional SMC & $\begin{array}{c}c=16 \\
\varepsilon=12,000 \\
k=50\end{array}$ & \\
\hline CSMC & $\begin{array}{c}c=15 \\
\varepsilon=18,000 \\
k=50 \\
a=0.1, b=0.02 \\
\beta=0.01, \gamma=3, l=-0.02\end{array}$ & \\
\hline
\end{tabular}

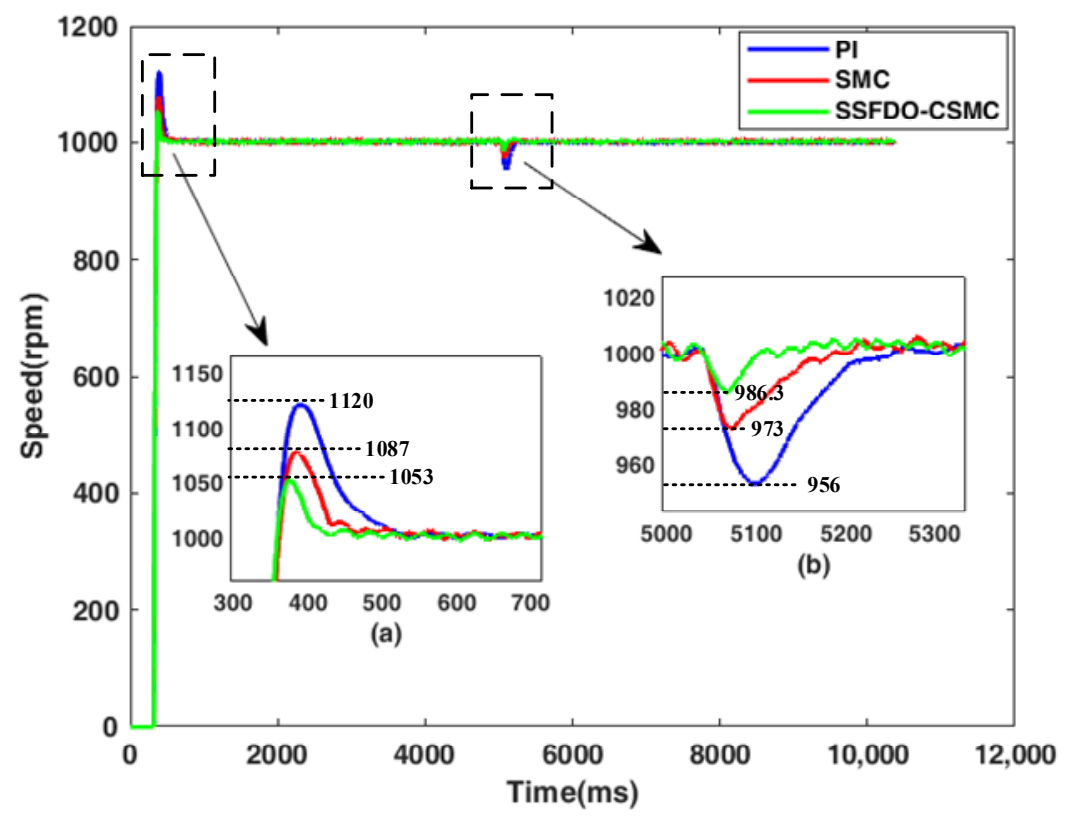

Figure 14. Actual speed response under the $0.112 \mathrm{~N} \cdot \mathrm{m}$ load: (a) starting performance, (b) disturbance rejection ability. 
Figure 14a shows that, under the same rise time, the overshoot of the CSMC is the smallest, whereas the adjustment time is the shortest. Figure $14 \mathrm{~b}$ shows that, when the same torque is loaded, the chattering of the CSMC is the smallest and the time to recover up to the steady state is the shortest. The motor speed overshoot, rapid change in the disturbance rejection ability, and adjustment time of the three control methods are shown in Table 6. The authenticity of the simulation results is verified by comparing the data in Table 6. It is again proven that the CSMC designed in this study is significantly better than the PI control and traditional SMC in the motor startup performance and disturbance rejection ability.

Table 6. Experimental speed changes and adjustment time under load mutation.

\begin{tabular}{cccc}
\hline Control Methods & PI Control & Traditional SMC & CSMC \\
\hline Rise time (s) & 0.045 & 0.045 & 0.045 \\
Maximum speed (rpm) & 1120 & 1087 & 1053 \\
Adjusting time (s) & 0.346 & 0.266 & 0.214 \\
Load speed (rpm) & 956 & 973 & 986.3 \\
Recovery time (s) & 0.185 & 0.129 & 0.059 \\
Overshoot & $12 \%$ & $8.7 \%$ & $5.3 \%$ \\
\hline
\end{tabular}

4.2.3. Experimental Verification of the Performance under Speed Step with Constant Torque

In the experimental tests, the initial speed was set to $1000 \mathrm{rpm}$, and a constant torque of $0.112 \mathrm{~N} \cdot \mathrm{m}$ was applied. Then, the speed was changed step by step, first decreasing from $1000 \mathrm{rpm}$ to $500 \mathrm{rpm}$, then increasing to $800 \mathrm{rpm}, 1000 \mathrm{rpm}$, and $1100 \mathrm{rpm}$, and finally returning to $1000 \mathrm{rpm}$. The simulation results are shown in Figure 15. Figure 15a shows the starting speed performance curve of the motor and Figure 15b shows the disturbance rejection ability of the motor. Figure $15 \mathrm{c}-\mathrm{e}$ shows the starting speed performance of the motor at different step speeds.

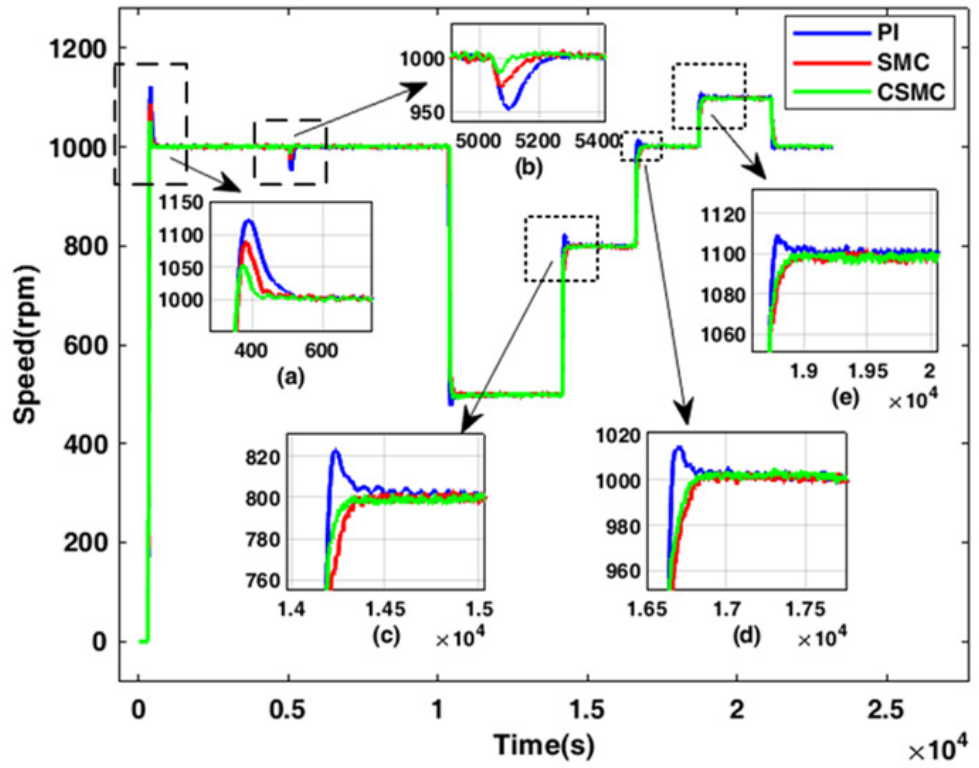

Figure 15. Actual performance response under speed step with $0.112 \mathrm{~N} \cdot \mathrm{m}$ torque: (a) starting performance, (b) disturbance rejection ability, (c-e) starting performance at different step speeds.

The results in Figure 15 show that the CSMC has the best tracking performance under the speed step with a constant torque of $0.112 \mathrm{~N} \cdot \mathrm{m}$. Compared with the PI control and traditional SMC, the CSMC can reach the target speed quickly and without overshoot. 


\section{Conclusions}

A CSMC based on SSFDO is proposed in this study for the control of PMSMs in EMAs. A new reaching law and disturbance observation feedforward compensation method are adopted by the controller to improve the response and disturbance rejection ability of the system. The stability is judged by the Lyapunov stability criterion, and the simulation and experimental verification are conducted using the Simulink and semi-physical platform. From the simulation and experimental results, it can be concluded that the performance, such as the overshoot, settling time, and disturbance rejection ability of the CSMC, was greatly improved compared with the PI controller and traditional SMC. The simulation and experimental results are consistent, indicating the effectiveness and superiority of the CSMC. However, in this paper, only the disturbance rejection ability of the CSMC under step load disturbance was studied. The disturbance rejection ability of the CSMC under continuous disturbance should also be further studied. Moreover, the effectiveness of the CSMC under different speeds should be further studied.

Author Contributions: Conceptualization, J.L., Y.Z., P.Z., J.W. and H.S.; data curation, Y.Z.; formal analysis, J.L., Y.Z., P.Z., J.W. and H.S.; funding acquisition, J.L.; investigation, Y.Z., P.Z., J.W. and H.S.; methodology, J.L., Y.Z. and P.Z.; project administration, J.L.; resources, J.L.; software, Y.Z. and P.Z.; supervision, J.L., Y.Z., P.Z., J.W. and H.S.; validation, J.L., Y.Z., P.Z., J.W. and H.S.; visualization, J.L., Y.Z., P.Z., J.W. and H.S.; writing—original draft, Y.Z.; writing—review and editing, J.L. and Y.Z. All authors have read and agreed to the published version of the manuscript.

Funding: This work were supported by the Joint Funding Project of Beijing Municipal Education Commission and Beijing Municipal Natural Science Foundation (granted No.: KZ201910005005) and the International Research Cooperation Seed Fund of Beijing University of Technology (granted No.: 2021A12).

Institutional Review Board Statement: Not applicable.

Informed Consent Statement: Written informed consent has been obtained from the patient(s) to publish this paper.

Data Availability Statement: Data sharing not applicable.

Conflicts of Interest: The authors declare no conflict of interest.

\section{References}

1. Huang, M.; Hu, X.W.; Li, S.J. Research on EMA servo control system. Civ. Aircr. Des. Res. 2019, 4, 31-35.

2. Cao, H.T.; Chen, F.; Chen, J. Review of the research on integrated steering gear technology. Ship Sci. Technol. 2017, 39, 1-7.

3. Guo, H.; Xing, W. Development of electromechanical actuation. Acta Aeronaut. Astronaut. Sin. 2007, $28,620-627$.

4. Zhao, C.; Zhou, J.M.; Li, X.M. Three-Closed-Loop servo control system of EMA based on permanent magnet synchronous motor. J. Chongqing Univ. Technol. 2016, 30, 104-111.

5. Yang, J.; Chen, W.; Li, S.; Guo, L. Disturbance/Uncertainty Estimation and Attenuation Techniques in PMSM Drives-A Survey. IEEE Trans. Ind. Electron. 2017, 64, 3273-3285. [CrossRef]

6. Zhou, L.J.; Zhao, D.B.; Ma, Y.M. Simulation Research on the Control Performance of EMA Servo Drive System. Mach. Electron. 2016, 34, 34-37.

7. Zhang, F.K.; Li, C.H.; Wang, K.; Li, J.C. Research on PMSM control system based on sliding mode speed controller. Autom. Instrum. 2020, 35, 30-34.

8. Zaihidee, F.M.; Mekhilef, S.; Mubin, M. Robust Speed Control of PMSM Using Sliding Mode Control (SMC)—A Review. Energies 2019, 12, 1669. [CrossRef]

9. Zhao, K.X. Research on Chattering Problem of Permanent Magnet Synchronous Motor Control System Based on Sliding Mode Variable Structure. Master's Thesis, Lanzhou Jiao Tong University, Lanzhou, China, 2019.

10. Liu, Y.Q.; Wang, B.H. PMSM sliding mode control based on improved reaching law. J. Hubei Univ. Automot. Technol. 2020, 34, 1-5.

11. Lin, C.M.; Yang, J. Sliding Mode Control of Permanent Synchronous Motor Based on Variable Exponential Reaching Law. Mot. Control Appl. 2020, 47, 21-24.

12. Zhou, Y.; Li, X.F.; Chen, X. Speed Control of Permanent Magnet Synchronous Motor Based on Novel Reaching Law. Mot. Control Appl. 2020, 47, 38-43.

13. Yan, H.L.; Li, B.B.; Hui, Z.H. Sliding mode control of Permanent Magnet Synchronous Motor undertime-varying disturbance. J. Terahertz Sci. Electron. Inf. 2021, 19, 324-330. 
14. Xiong, H.L.; Shen, Y.X. Study on PMSM Control Strategy Based on Improved Second Order Sliding Mode Controller. Micromotors 2020, 48, 50-57.

15. Zhou, C.J.; Meng, J.Z.; Zhang, W.; Fu, W.C.; Shen, M.X. Study on fractional sliding mode control of permanent magnet synchronous motor based on vector control. China Plant Eng. 2021, 11, 91-93.

16. Wu, D.H.; Yang, D.L.; Chen, J.B. Vector control of PMSM based on sliding mode observer. J. Syst. Simul. 2018, 30, $4256-4267$.

17. Chen, W.-H.; Yang, J.; Guo, L.; Li, S. Disturbance-observer-based control and related methods-An overview. IEEE Trans. Ind. Electron. 2016, 63, 1083-1095. [CrossRef]

18. Liu, Y.-C.; Laghrouche, S.; N'Diaye, A.M. Cirrincione. Hermite neural network-based second-order sliding-mode control of synchronous reluctance motor drive systems. J. Frankl. Inst. 2021, 358, 400-427. [CrossRef]

19. Liu, Y.-C.; Laghrouche, S.; Depernet, D.; Djerdir, A.; Cirrincione, M. Disturbance-observer-based complementary sliding-mode speed control for PMSM drives: A super-twisting sliding-mode observer-based approach. IEEE J. Emerg. Sel. Top. Power Electron. 2020. [CrossRef]

20. Dai, C.; Guo, T.; Yang, J.; Li, S. A Disturbance observer-based current-constrained controller for speed regulation of PMSM systems subject to unmatched disturbances. IEEE Trans. Ind. Electron. 2021, 68, 767-775. [CrossRef]

21. Qu, L.; Qiao, W.; Qu, L. An extended-state-observer-based sliding-mode speed control for permanent-magnet synchronous motors. IEEE J. Emerg. Sel. Top. Power Electron. 2021, 9, 1605-1613. [CrossRef]

22. Zhu, D.H.; Wang, Y. Speed Control of PMSM Based on New Sliding Mode Reaching Law. Micromotors 2021, 49, 34-38.

23. Lou, P.B.; Huang, R.N. Adaptive inversion sliding mode control of PMSM based on nonlinear disturbance observer. Micromotor 2020, 48, 32-40.

24. Li, Z.; Hu, G.D.; Cui, J.R.; Liu, G.Y. Sliding-mode Variable Structure Control with integral action for Permanent Magnet Synchronous Motor. Proc. CSEE 2014, 34, 431-437.

25. Zhao, F.; Luo, W.; Gao, F.Y.; Yu, J.L. An improved sliding mode control for PMSM considering sliding mode chattering and disturbance compensation. J. Xi'an Jiao Tong Univ. 2020, 54, 28-35.

26. Yu, L.; Hu, B.X.; Wei, K.Y. Modern Permanent Magnet Synchronous Motor Control Principle and MATLAB Simulation, 1st ed.; Beijing University of Aeronautics and Astronautics Press: Beijing, China, 2016; pp. 4-55.

27. Wang, A.M.; Wei, S.J. Sliding Mode Control of Permanent Magnet Motor Based on Improved Exponential Reaching Rate. J. North China Electr. Power Univ. 2020, 47, 50-57.

28. Xia, X.Q.; Zhang, B.; Li, X.T. Low Speed Sliding Mode Control of Permanent Magnet Synchronous Motor Based on Extended State Observer. Opt. Precis. Eng. 2019, 27, 2628-2638. 